\title{
Mesothelioma From Household Asbestos Exposure
}

\author{
Flavia D'Agostin ${ }^{*}$, Paola De Michieli' ${ }^{1}$ Corrado Negro'
}

'Occupational Medicine Unit, Department of Surgical and Medical Sciences of Health University of Trieste, University of Trieste, Trieste, Italy

Article Info

\section{Article Notes}

Received: December 13, 2017

Accepted: January 02, 2018

\section{${ }^{*}$ Correspondence:}

Dr. Flavia D'Agostin, Department of Surgical and Medical Sciences of Health University of Trieste, Occupational Medicine Unit, Via Pieta 2/2, 34100 Trieste,

Italy; Telephone: +390403992518;

Email: fladagostin@yahoo.it

() 2018 D'Agostin F. This article is distributed under the terms of the Creative Commons Attribution 4.0 International License.

\section{Keywords}

Mesothelioma

Household exposure

Epidemiology

Family members

Asbestos-exposed workers

Latency

\section{ABSTRACT}

Non-occupational exposure to asbestos is a hazard that may contribute to the burden of mesothelioma over the next decades. Such exposure may result from cohabitation with an asbestos worker and the handling of his/her work clothes. This paper reviews the features of mesothelioma from domestic exposure reported by the literature. Household-exposure mesothelioma cases are more likely to be 1) female (primarily wife), 2) diagnosed with pleural mesothelioma 3) exposed and, in some cases, 4) diagnosed at a younger age, and to have a 5) longer latency and 6) similar lung asbestos concentrations compared to occupational cases. Non-occupational subjects are more likely to be under-recognized than those with occupational exposure. This underlines the ongoing importance of exposure history in enhancing early diagnosis and the need of a framework for insurance and welfare protection for mesothelioma cases induced by non-occupational exposure to asbestos.

\section{Introduction}

Malignant mesothelioma (MM) is a rare tumor arising most frequently from the mesothelial lining of the pleura and the peritoneum. Patients commonly show unspecific symptoms (i.e., dyspnoea, chest wall pain, pleural effusion, increased abdominal girth and weight loss). Diagnosis usually occurs at a late stage and in untreated patients, median survival is less than one year ${ }^{1}$.

MM is causally related to asbestos exposure with an aetiological fraction above $80 \%{ }^{2}$. The International Agency for Research on Cancer recently confirmed that all types of asbestos cause cancer in humans ${ }^{3}$.

Many western countries are currently going through an MM epidemic, considering the extensive use of asbestos from 1950 to 1985 in a large number of industries (e.g., construction and shipbuilding) and the long latency period (around 40 years) since the beginning of exposure. Asbestos is still used in many countries of Asia, South America, Africa and former Soviet Union ${ }^{4}$. The incidence rates of pleural MM in a large proportion of Europe are in the range of 10-20 cases per million. The highest incidence rates of disease, about 30 cases per million, are reported from Australia and the United Kingdom ${ }^{5}$. In Italy, the standardized incidence rate for pleural MM in 2008 was 3.84 (cases per 100,000 inhabitants) for men and 1.45 for women ${ }^{4}$. The incidence rates of peritoneal MM in industrialized countries range from 0.5 to about 3 cases per million population in men and between $0.2-2$ cases per million in women ${ }^{6}$. 
In the countries that banned asbestos, most cases of mesothelioma show a history of asbestos exposure at work, while a proportion of cases do not report any occupational exposure throughout their working life. Therefore, assessment of the spread and of the health effects of nonoccupational asbestos exposure continues to be of great public interest because related to peculiar circumstances such as living with asbestos workers (domestic exposure) or close to asbestos mines or manufacturing plants, or naturally occurring asbestos fibers, or in asbestos-insulated buildings (environmental exposure), which may be still incompletely controlled ${ }^{7}$. Non-occupational exposures of this type were found to account for $10.2 \%$ of cases in the period 1993-2008 in Italy ${ }^{4}$, but they have been implicated in up to $30 \%$ of current presentations in the United States and are predicting to account for an increasing proportion of disease ${ }^{8}$.

The domestic exposure that results from cohabitation with an asbestos worker and handling of his/her work clothes has been investigated in many studies. This paper presents a review of the medical literature and analyzes the features of MM cases occurring among household contacts of asbestos workers.

\section{Descriptive epidemiology}

The risk of MM among household members of asbestos workers has long been recognized since the report of Newhouse and Thompson ${ }^{9}$ (1965). Review of the literature on this exposure is difficult for many reasons ${ }^{10}$. On the one hand, many of the descriptions are of single or of a small number of cases ${ }^{11-13}$. Huncharek et al. ${ }^{11}$ (1989) reported that a shipyard machinist's wife, who had washed his asbestos-contaminated work clothes at home, died of pleural mesothelioma. An article by Schneider et al. $^{12}$ (1996) reported 5 pleural mesothelioma deaths (5 wives of asbestos-industry workers) exclusively due to domestic exposure. Bianchi et al. ${ }^{13}$ (2004) found 5 patients in a total of 40 familial mesotheliomas who had been exposed at home while cleaning their relatives' working clothes. On the other hand, in several studies, the identification of household exposure as the mechanism for family mesothelioma has been complicated by reporting family cases with their own occupational ${ }^{14,15}$ or other non-occupational exposures such as the neighborhood of industrial sources or asbestos present in buildings of employment ${ }^{16,17}$. Finally, in other reports, family cases resulting from household exposure have been confounded with a possible genetic predisposition to mesothelioma reported in consanguineous family members who have been occupationally exposed ${ }^{14,18}$.

Case series that report a considerable number of household-exposure mesothelioma cases have been published since 1990. Roggli and coworkers ${ }^{19}$ (1997) reported 33 female mesothelioma cases attributable only to household exposure. Miller ${ }^{10}$ (2005) found 32 mesothelioma cases (27 pleural, 5 peritoneal) with domestic asbestos exposure; 10 of these cases presented pleural plaques, 4 of whom also had asbestosis. Marinaccio et al. ${ }^{4}$ (2015) listed 12,065 cases from the Italian Mesothelioma Register 1993-2008 of whom 530 (4,4\%) had lived with a cohabitant occupationally exposed. Estimated latency period -time from asbestos exposure to disease diagnosisfor household exposure (50 years) was longer than for occupational exposure (46 years), while the age of starting exposure in family cases (17.4 years) was lower than in occupational ones (22.5 years). A recent study carried out in a ship-building district in northeastern Italy, reported 35 pleural mesothelioma cases (33 females -predominantly wives- and 2 males) in relatives of asbestos workers who had lived in the same household. Occupational exposures of household contacts were in industrial activities well known to cause mesothelioma among workers, such as shipyard. Asbestosis was found in 7 women, 3 of these had pleural plaques as well. As further evidence of previous exposure, asbestos bodies were found on routine lung sections in 4 cases $^{20}$. A previous study in the area found that the asbestos body concentrations among household contacts of asbestos workers were comparable to those found in shipyard-industry employees ${ }^{15}$.

Several case-control and cohort studies have confirmed the increased risk of MM in family members of asbestos workers. A case-control study from England reported 9 cases of MM among women (7 wives and 2 sisters of asbestos workers) with household exposure ${ }^{9}$. In a casecontrol study among New York females, Vianna and Polan ${ }^{21}$ (1978) estimated an odds ratio (OR) of 8.0 (95\% CI, 1.064.0) for household exposure. A case-control study in Casale Monferrato (Italy), estimated a relative risk (RR) of 3.1 for spouses (both sexes) of asbestos-cement workers ${ }^{22}$. In a previous multicentric study on $\mathrm{MM}$, the odds ratio (OR) was 7.8 (95\% CI, 1.7-36.2) for domestic exposure ${ }^{17}$. A more recent study in Casale Monferrato showed a statistically significant increase in both pleural cancer mortality and pleural MM incidence in a cohort of non-occupationally exposed wives of asbestos-cement workers ${ }^{23}$. A previous cohort study reported 3 cases of mesothelioma (a 40-yearold son and two daughters, aged 41 and 51 years, of amosite workers) who had been exposed to asbestos at home during their childhood ${ }^{24}$.

Data on related exposure fiber concentrations are limited. Some simulation studies measured air concentrations during handling of asbestos contaminated clothes suggesting that potential take-home exposures to household contacts are a fraction, perhaps $1 \%$, of occupational exposure ${ }^{25}$. However, studies are not available to quantify airborne exposure concentrations for laundry 
handling where the worker contact was in a high exposure occupation $^{26}$.

\section{Discussion}

The overview of literature confirms the increased risk of MM from domestic exposure for relatives of occupationally exposed workers. Many researchers agree that occupational as well as non-occupational exposure may be anything from very heavy to very low. While exposure in non-occupational circumstances is generally much lower than in occupational settings, the levels may not be negligible ${ }^{27}$. Nicholson et al. ${ }^{28}$ (1980) found that chrysotile asbestos concentrations in the air of the homes of 13 asbestos mine and mill employees ranged from $50 \mu \mathrm{g} / \mathrm{m}^{3}$ to $>2000 \mu \mathrm{g} / \mathrm{m}^{3}$. Brushing clothes might give peaks of $>100$ fibers $/ \mathrm{ml}$, which may remain for years in the house and be airborne again whenever disturbed $^{29}$. Thus, the typical non-occupational exposure is low or very low, but occasional high exposure occurs when there is a disturbance of some kind ${ }^{30}$. Moreover, while fiber dose may be lower in the non-occupational settings, the duration of exposure may be much longer in the nonoccupational as compared with the occupational setting, because the asbestos fibers permeate the environment. Therefore, cumulative exposure may be comparable between occupational and non-occupational cases ${ }^{31}$. In some family cases, the asbestos body concentration or the fiber content in lung tissue from such exposure was found to be similar to that of most asbestos-exposed trades, such as shipyard ${ }^{11,15}$. Other studies report the presence of asbestosis and pleural plaques in cohabitants of asbestos workers as a further evidence of previous exposure ${ }^{10,20}$.

Since many works commonly associated with asbestos exposure historically exclude women, non-occupational exposure occurred in women more frequently than in men. In most, if not all, studies the majority of the householdexposure mesothelioma cases were women (predominantly wives). A cohort study by Ferrante et al. ${ }^{23}$ (2007) focuses on wives (i.e., the individuals who were more heavily exposed in the household because of dust from handling and cleaning work clothes). Other reports show that not only wives but also sons and daughters are at risk from asbestos brought home by exposed workers ${ }^{10,13,20,24}$. An earlier age at first exposure has been documented among family cases in contrast with occupational cases ${ }^{4}$ : this may be attributed to the high number of cases with household exposure during childhood/adolescence. On the one hand, household exposure has been suggested as the source for mesothelioma presenting at an earlier age $\mathrm{e}^{10}$. Kane et al. $^{32}$ (1990) reported five cases of pleural mesothelioma younger than 40 years attributable to household exposure during childhood. On the other hand, the higher mean age at diagnosis (60 years or grater) reported in several case series shows that household exposure should not be ruled out when mesothelioma is detected in an older individual ${ }^{4,10,20}$. Some familial mesothelioma cases presented dual relationship (e.g., daughter and wife, wife and mother, daughter and sister $)^{10,20}$. The majority of mesothelioma cases among household contacts were pleural. However, some studies provided evidence of an increasing risk of peritoneal mesothelioma among women following household exposure ${ }^{9,21}$.

Recent reports have shown larger latency times among household exposed cases than those found among the occupationally exposed ones, suggesting that with lower exposures latency time increases ${ }^{4,10,20}$. Wives had a shorter latency than offspring, despite the similar duration of exposure $^{10,20}$. This may be consistent with a greater burden of asbestos in wives. It is necessary to underline that it is particularly complex to identify the start of asbestos exposure for mesothelioma cases of non-occupational origin. In these analyses, the first year of cohabitation (or the year of first exposure beginning for the cohabitant) was considered as the onset of asbestos exposure. For example, for each wife, the time of first exposure to asbestos was considered to have coincided with the date of marriage or the date the husband was hired, whichever was later. As a matter of fact, the beginning of a work period could not exactly correspond to the beginning of exposure to asbestos, and it could lead to an overestimation of latency time $\mathrm{e}^{33}$.

The survival from mesothelioma has been shown to be poor (median 11 months), which is consistent with the typical pattern of survival for $\mathrm{MM}^{20}$. Nevertheless, an early report demonstrated a wide range of survival following mesothelioma diagnosis in a group of 64 untreated patients. The median survival in this group was 18 months and in seven of them survival exceeded 4 years, despite the absence of any specific treatment ${ }^{34}$. Moreover, a more recent report performed in a consecutive, unselected series of mesothelioma patients with pleural effusion, found a mean survival of nearly 2 years (median 19 months) after thoracoscopic talc poudrage $\mathrm{e}^{35}$.

\section{Conclusions}

Non-occupational subjects are more likely to be underrecognized than those with occupational exposure because of recall and gender bias. Considered the long latency period involved, such exposure can be rather remote and involve poor recollection ${ }^{36}$. Thus, it is , of course, possible that a great number of female mesothelioma cases who have not been attributed to asbestos, should be due to household exposure unknown (or forgotten by) to the patients themselves. Many authors emphasize the importance of collecting a thorough occupational and non-occupational exposure history when evaluating a patient with signs or symptoms of a thoracic or abdominal malignancy. The overview of literature suggests that household asbestos exposure is a 
hazard that may contribute to the burden of MM over the next decades. This underlines the ongoing importance of research directed towards early diagnosis and disease management ${ }^{37}$ as well as the need of a framework for insurance and welfare protection for mesothelioma cases induced by non-occupational exposure to asbestos ${ }^{4}$.

\section{Conflict of interest statement}

\section{None declared}

\section{References}

1. Milano MT, Zhang H. Malignant pleural mesothelioma: a populationbased study of survival. J Thorac Oncol. 2010; 5: 1841-8.

2. McDonald JC, McDonald AD. The epidemiology of mesothelioma in historical context. Eur Respir J. 1996; 9: 1932-42.

3. IARC. Arsenic, metals, fibres, and dusts. IARC Working Group on the Evaluation of Carcinogenic Risks to Humans. IARC Monogr Eval Carcinog Risks Hum. 2012; 100: 11-465.

4. Marinaccio A, Binazzi A, Bonafede M, et al. ReNaM Working Group. Malignant mesothelioma due to non-occupational asbestos exposure from Italian national surveillance system (ReNaM): epidemiology and public health issues. Occup Environ Med. 2015; 72: 648-55.

5. Bianchi C, Bianchi T. Malignant mesothelioma: global incidence and relationship with asbestos. Ind Health. 2007; 45: 379-87.

6. Boffetta P. Epidemiology of peritoneal mesothelioma: a review. Ann Oncol. 2007; 18: 985-90.

7. Goldberg M, Luce D. The health impact of non-occupational exposure to asbestos: what do we know? Eur J Cancer Prev. 2009; 18(6): 489-503.

8. Robinson BW, Lake RA. Advances in malignant mesothelioma. N Engl J Med. 2005; 353: 1591-603.

9. Newhouse ML, Thompson H. Mesothelioma of pleura and peritoneum following exposure to asbestos in the London area. Br J Ind Med. 1965; 22: 261-9.

10. Miller A. Mesothelioma in household members of asbestos-exposed workers: 32 United States cases since 1990. Am J Ind Med. 2005; 47: 458-62.

11. Huncharek M, Capotorto JV, Muscat J. Domestic asbestos exposure, lung fiber burden, and pleural mesothelioma in a housewife. $\mathrm{Br} \mathrm{J}$ Ind Med. 1989; 46 (5): 354-5.

12. Schneider J, Straif K, Woitowitz HJ. Pleural mesothelioma and household exposure. Rev Environ Health. 1996; 11: 65-70.

13. Bianchi C, Brollo A, Ramani L, et al. Familial mesothelioma of the pleura. Ind Health. 2004; 42(2): 235-9.

14. Hammar SP, Bockus D, Remington F, et al. Familial mesothelioma: a report of two families. Hum Pathol. 1989; 20: 107-12.

15. Bianchi C, Brollo A, Ramani L, et al. Asbestos-related mesothelioma in Monfalcone, Italy. Am J Ind Med. 1993; 24(2): 149-60.

16. Iscovich J, Fischbein A, Witt-Kushner J, et al. Malignant mesothelioma in Israel, 1961-1992. Int J Occup Environ Health. 1961; 5: 157-63.

17. Magnani C, Agudo A, Gonzalez CA, et al. Multicentric study on malignant pleural mesothelioma and non-occupational exposure to asbestos. Br J Cancer. 2000; 83: 104-11.
18. Krousel T, Garcas N, Rothschild H. Familial clustering of mesothelioma: a report on three affected persons in one family. Am J Prev Med. 1986; 2: $186-88$.

19. Roggli VL, Oury TD, Moffatt EJ. Malignant mesothelioma in women. Anat Pathol. 1997; 2: 147-63.

20. D’Agostin F, De Michieli P, Negro C. Pleural mesothelioma in household members of asbestos-exposed workers in Friuli Venezia Giulia, Italy. IJOMEH. 2017; 30(3): 419-31.

21. Vianna NJ, Polan AK. Non-occupational exposure to asbestos and malignant mesothelioma in females. Lancet. 1978; i: 1061-3.

22. Magnani C, Dalmasso P, Biggeri A, et al. Increased risk of malignant mesothelioma of the pleura after residential or domestic exposure to asbestos: a case control study in Casale Monferrato, Italy. Environ Health Perspect. 2001; 109(9): 915-9.

23. Ferrante D, Bertolotti M, Todesco A, et al. Cancer mortality and incidence of mesothelioma in a cohort of wives of asbestos workers in Casale Monferrato, Italy. Environ Health Perspect. 2007; 115: 1401-5.

24. Anderson H. Family contact exposure. In: Proceedings of the World Symposium on Asbestos, 25-27 May 1982, Montreal, Quebec, Canada, 349-62 Montreal: Canadian Asbestos Information Centre.

25. Sahmel J, Barlow CA, Simmons B, et al. Evaluation of take-home exposure and risk associated with the handling of clothing contaminated with chrysotile asbestos. Risk Anal. 2014; 34: 1448-68.

26. Goswami E, Craven V, Dahlstrom DL, et al. Domestic asbestos exposure: a review of epidemiologic and exposure data. Int J Environ Res Public Health. 2013; 10: 5629-70.

27. Goldberg M, Luce D. Can exposure to very low levels of asbestos induce pleural mesothelioma? Am J Respir Crit Care Med. 2005; 172: 939-40.

28. Nicholson WI, Rohl AN, Weismann I, et al. Environmental asbestos concentrations in the United States. IARC Sci Publ. 1980; 2(30): 823-7.

29. Browne K. Asbestos-related mesothelioma: epidemiological evidence for asbestos as a promoter. Arch Environ Health. 1983; 38: 262-6.

30. Hillerdal G. Mesothelioma: cases associated with non-occupational and low dose exposures. Occup Environ Med. 1999; 56: 505-13.

31. Metintas S, Metintas M, Ucgun I, et al. Malignant mesothelioma due to environmental exposure to asbestos: follow-up of a Turkish cohort living in a rural area. Chest. 2002; 122: 2224-9.

32. Kane MJ, Chahinian AP, Holland JF. Malignant mesothelioma in young adults. Cancer. 1990; 65: 1449-55.

33. Marinaccio A, Binazzi A, Cauzillo G, et al. ReNaM Working Group. Analysis of latency time and its determinants in asbestos related malignant mesothelioma cases of the Italian register. Eur J Cancer. 2007; 43: 2722-8.

34. Law MR, Gregor A, Hodson ME, et al. Malignant mesothelioma of the pleura: a study of 52 treated and 64 untreated patients. Thorax. 1984; 39: 255-9.

35. Aelony Y, Yao JF. Prolonged survival after talc poudrage for malignant pleural mesothelioma: case series. Respirology. 2005; 10: 649-55.

36. Haber SE, Haber JM. Malignant mesothelioma: a clinical study of 238 cases. Ind Health. 2011; 49(2): 166-72.

37. Robinson BM. Malignant pleural mesothelioma: an epidemiological perspective. Ann Cardiothorac Surg. 2012;1(4): 491-6. 